\section{DENUNCIA, HUMOR Y PASIÓN EN LA NARRATIVA DE COLOMBINE}

\author{
Gregorio Torres Nebrera \\ Universidad de Extremadura \\ Avda. Rodríguez de Ledesma, 2 \\ 10001 Cáceres \\ gtnebrera@unex.es
}

\begin{abstract}
In this paper several thematic aspects in the narrative of Carmen de Burgos are analyzed (denunciation of social defects, humoristic perspectives and symbolization of love passion) on some of her most remarkable novels: El veneno del arte, Los anticuarios, El tio de todos and Puñal de claveles.
\end{abstract}

KEY WORDS: Carmen de Burgos; narrative; thematic analysis; social denunciation; humour and passion.

Muchos son los temas que se cruzan en la extensa obra narrativa de Carmen de Burgos, desde el más central de todos, el de la reivindicación feminista. Título a título la prolífica y voluntariosa narradora fue pasando revista a los problemas de su tiempo tal y como ella creía verlos y enfocarlos. He elegido tres de esos ángulos de visión, que por supuesto se alternan o combinan con otros en bastantes de sus títulos, pues nadie puede negar que en las novelas, cortas y largas, de Colombine hay denuncia de ciertos comportamientos sociales, hay pasión a raudales y también hay modos humorísticos de presentar ciertas caras de esa realidad referencial. $Y$ esos tres temas -denuncia, humor y pasión- voy a examinarlos en cuatro títulos que están estratégicamente elegidos a lo largo de los veinticinco años que abarcó su cronología de novelista, y de las tres etapas que se han señalado en esa trayectoria, pues uno se sitúa en los años de inicio, otros dos en los años centrales de su biografía literaria y, finalmente, he seleccionado una de sus últimas novelas cortas, compuesta un año antes, tan sólo, de su muerte. 0 sea, voy a tratar la triada de aspectos anunciados en estas cuatro novelas de Colombine: El veneno del arte (de 1910, siendo su primera colaboración en la serie de "Los Contemporáneos", al tiempo que se afilia al PSOE, viaja con Ramón por Europa y traduce la deliciosa novelita de Longo Dafnis y Cloe); Los anticuarios (de 1919, el año en que abandona la agrupación socialista por su ambigüedad a la hora de defender el sufragio femenino,

\section{CONDEMNATION, HUMOUR AND PASSION IN THE COLOMBINE NARRATIVE}

RESUMEN: En este artículo se abordan diversos aspectos temáticos de la narrativa de Carmen de Burgos (denuncia de defectos sociales, perspectivas humoristicas y simbolización de la pasión amorosa) en algunas de sus principales novelas: El veneno del arte, Los anticuarios, El tío de todos y Puñal de claveles.

PALABRAS CLAVE: Carmen de Burgos; narrativa; análisis temático; denuncia social; humor y pasión.

vive un tiempo en Estoril, reponiéndose de una importante dolencia cardiaca, imparte clases en la Universidad de Lisboa y publica su célebre biografía de Larra); El tío de todos (de 1925, coincidiendo con un dilatado y exitoso viaje a México y Cuba) y Puñal de claveles (de 1931, cuando es propuesta para un sillón académico, aparece su biografía del general Riego y funda una logia feminista)'. Cuatro calas que tienen en cuenta las dos modalidades de su escritura narrativa (novelas largas y novelas cortas) y que suponen, me parece, una suficiente muestra selectiva de su faceta como novelista ${ }^{2}$.

\section{LA DENUNCIA}

A Colombine le irrita la impostura del joven aspirante a artista, que intenta tirar por tierra los valores acreditados, por viejos, para subirse sobre ellos como si fueran los derribos de un desmonte. En la novela El veneno del arte presenta a esos jóvenes mal vestidos y desastrosamente peinados que hacen gala de su bohemia malsana como exigida patente de artista. Porque -premisa que la autora rechaza desde la severa ironía- "no se concebía que un hombre fuese bien vestido, comiera todos los días, dedicase horas al estudio, cumpliera sus compromisos y estuviera capacitado para ser genio" (VA, 224). Colombine denuncia 
la falta de información, y de formación, en esa nueva pléyade de presuntos artistas sin bagaje que llenan salones de buen tono en los años de la bohemia artística, y que hacen incluso ostentación de su ignorancia, o, a lo máximo, se presentan con "erudición de enciclopedia barata". Ridiculiza su sentido de la "rebeldía", que es tapadera de la mayor inacción, y de la irritante petulancia, como la de aquel novel dramaturgo que "aseguraba que eran suyas todas las obras de Benavente, el cual se inspiró en los manuscritos que le sometiera de manera inexperta" (VA, 225).

En otro momento de la misma novela, y a través de un personaje que bascula entre la ensoñación delicuescente y el spleen, se denuncia el frecuente naufragio de tantos jóvenes aspirantes a artistas en un mundo en el que realmente se desprecia el arte, y por tanto acaban sucumbiendo quienes se dejan llevar por el canto de sirena del triunfo fácil, sin fundamentar previamente en el esfuerzo, en la constancia, en el trabajo la escala para llegar a la difícil meta de la genialidad. El dibujo que servía de portada a la primera edición de El veneno del arte, en la colección de "Los Contemporáneos", y debido al dibujante FernándezMota, es expresivo de esta denuncia: en ella vemos una hermosa ánfora que se eleva sobre una superficie acuosa, de la que se vierte un líquido en el que bebe una serpiente enroscada a su basamento, y varios cuerpos inertes flotando sobre ese piélago venenoso, víctimas de haber gustado el veneno aludido en el título.

En la misma novela, Colombine deja caer una breve, pero contundente crítica, sobre la educación en los colegios jesuitas -ella que fue de profesión y vocación pedagoga- aludiendo a ciertas prácticas pedófilas (ya señaladas por Pérez de Ayala en $A M D G$ ), y junto a esta denuncia hace también la de las mujeres desvergonzadas que van a la busca y captura de un hombre un poco bobo, pero buen partido, fingiendo ser inocentes vírgenes dignas de delicado respeto. Una suerte de encubierta prostitución que, al final del relato, hace extensiva a los hombres de una clase aristocrática tronada que también fingen ser hipócritas maridos de buen tono cuando verdaderamente su inclinación es homófila, y la sacrifican en aras de una vida acomodada y convencional, en medio de la hipocresía de una sociedad de buen tono.

Pero sobre lo que Carmen de Burgos carga la mano en El veneno del arte es sobre la canallesca vida bohemia, en la que encuentra una perversa inversión de valores, sobre todo cuando conecta esa bohemia malsana con escandalosas reuniones de jovencitos afeminados que se comportan como las representantes del sexo contrario, de las que se burlan inmisericordes; práctica que le hace lamentar: " $\mathrm{Q}$ Qué fatalidad aborrecer a las mujeres como seres inferiores y complacerse en imitarlas!" (VA, 252). Acabando la novela, de Burgos, por boca de una hipercrítica artista del bel canto, dictamina sobre los caminos del arte y de quienes se arrostran a seguirlos, y en donde tantos se extravían porque toman el camino equivocado. Llegar a la cima del arte, con sensatez, es únicamente la consecuencia de una concienzuda preparación y de un constante trabajo, y todos los que no hacen eso acaban destrozados en su vano deseo de llegar a una cima inexistente. Gustaban un veneno que se resolvía en "encanallamiento moral". A la altura de 1910, en pleno decadentismo, Colombine formula una contundente condena de sus prácticas y de su puesta en escena, que debilita y consume hasta la anulación: "Todos ellos enfermaban, se destruian en plena juventud con los vicios y la mala alimentación" (VA, 269), pero en ninguno se advertía que hubiese escogido el honrado camino del trabajo. Colombine se declara contraria al malditismo de Baudelaire y de Lorraine, porque sólo cosecha cadáveres de una osadía sin sentido, o de una falsedad que destruye más que aporta. Son artistas tan inanes y fatuos que sólo atienden a la tasa del mejor postor, aunque sea renunciando a todos sus principios, y que subsisten degradados y envenenados del todo, hasta que sucumben.

La mixtificación, la hipocresía y la falsedad de sentimientos, de conceptos y de moral fue uno de los males sociales que más preocupó, y denunció, Colombine, en gran parte porque se sintió victima de ese malévolo juego social de pasar lo falso por excelente, lo malo por bueno, lo inmoral por honrado. La conciencia de que ese mal del siglo era omnímodo y omnipotente y que podía encontrarse en cualquiera de los ámbitos sociales conocidos y analizados, en España y en la Europa que visitó, se concretó en una de sus novelas más ambiciosas de su larga producción, Los anticuarios, en la que toma pie en una imaginada familia de negociantes y comerciantes españoles en el arte de comprar barato y vender caro mil y un objetos, que se instala en París, en donde se alza con la primacía de un negocio pujante que se configura como símbolo de la no menos pujante hipocresía social, de una picaresca que habita de forma idéntica tanto en los bajos fondos como en los 
altos niveles sociales, y que usa del dinero como la única mercancía cierta y circulante que se obtiene de engañar a fatuos ambiciosos, vacunando de cualquier escrúpulo moral a los que se mueven y triunfan en ese activo comercio de la transacción de lo falso, de lo inauténtico.

Refiriéndose a la concreta práctica del negocio de antigüedades, Carmen de Burgos empieza por reconocer, y denunciar, que España era propicia al surgimiento y medro de ese negocio, pues en su pais "las antigüedades de mérito son comunes, hasta en las casas de los aldeanos, y donde se vendian todas, por raras que fuesen, lo mismo los recuerdos de antepasados que las reliquias de los templos" (LA, 5-6). Es consciente Colombine, como la protagonista de su novela, verdadera alma y guía del provechoso negocio, de que "el mundo de los anticuarios, con sus fraudes y su manias, era un mundo aparte" (LA, 9), y también de que "aquel negocio era maravilloso, más lucrativo que todo comercio, que toda industria, y hasta más que la usura. Se podian ganar miles por ciento" (LA, 27).

Para hacer esta novela sorprende la excelente documentación de su autora, que muestra un concienzudo conocimiento del tipo de pieza -en muebles, en joyas, en arte, en objetos varios- que le interesa al buen anticuario, sus tácticas gananciosas para comprar barato lo que luego se sabe vender caro y los muchos recursos de la restauración de los objetos que expone en su casa de antigüedades $y$, sobre todo, de la mixtificación, del engaño, tanto en comprar con ventaja, incluso lo prohibido, como en vender a precios exorbitantes piezas de falsos siglos de historia, y que el comprador se marche creyendo que tiene una envidiable porción del pasado en sus manos de coleccionista, encapsulado en su estéril egoísmo de contemplar bajo siete llaves lo que es ya sólo posesión personal, frente a la democrática exposición al goce de todos de los objetos valiosos y artísticos de los museos. Por ello recoge Colombine la inquina que los anticuarios de raza muestran por los dichos museos, que son a la vez, para ellos, incitantes objetos de deseo y derrochones expositores de la belleza a bajos precios, o gratis.

Pero si en el gremio de los anticuarios quiere ver nuestra narradora una expresiva simbolización del mundo como mercadeo de valores alterados, mezcla informe de infravalores y de supravalores, la novela le sirve también para perfilar un personaje femenino y voluntarioso, capaz y decidido, como pocos en su narrativa, la alegre y vitalista Adelina, que de humilde prendera en Madrid, a poco de casada, logra en unos años convertirse en una de las más sagaces, prestigiosas y codiciadas anticuarias del siempre mundano y cosmopolita París.

El trasiego del mercado de antigüedades, sus luces y sus sombras, lo resume oportunamente Colombine en estos dos párrafos consecutivos de su novela: "Los que vendian aquellas cosas viejas creían que habian engañado a los anticuarios, aunque siempre les quedaba el resquemor de si valdrían más de lo que pensaban. Luego los anticuarios trataban de engañar a los compradores, como habian engañado a los que les vendieron" $(L A, 34)$. Continuamente en la novela se alude a lo fácil que resultaba en aquella época el tráfico con bienes artísticos españoles, y de qué modo los más audaces y poderosos anticuarios extranjeros arramblaban, impunemente, con multitud de muestras del tesoro eclesiástico -incluidas reliquias de santos- en manos, entonces, de incultos, y sobre todo, muy necesitados curas de pueblo, que regentaban iglesias y parroquias olvidadas del obispado de turno. Esos curas que, en opinión de la narradora, "decían que era una necedad eso de conservar el tesoro artístico de España, y no era cosa de que los condenaran a morirse de hambre mirando sus alhajas inútiles" $(L A, 37)$. $Y$ todo ello sin que el Estado saliera al paso de una sangría deshonrosa de nuestro patrimonio cultural. Un ejemplo de una compra fraudulenta y ventajosa es la que se refiere acaecida, precisamente, en un convento de clausura de Toledo, la ciudad que bien conoció Carmen de Burgos, señalando sus luces y sus sombras, una mezcla de admiración y de rechazo ${ }^{3}$, como lo que siente la anticuaria Adelina de su novela.

En un documentado capítulo del libro, el VIII, Colombine da noticias suficientes de su conocimiento de primera mano de aquel abigarrado mundo de los anticuarios, concentrados en una conocida calle parisina, trasladando a su novela diferencias y semejanzas de los distintos establecimientos de franceses, italianos, y turcos, entre los que se amontonaban objetos de muy diversa catadura y procedencia (pinturas, telas, porcelanas, armas, joyas) y cómo entre todas aquellas tiendas iba destacando, con personalidad propia, la de los españoles, de cuyas mercancías se hace un completísimo inventario. $Y$ en lo que más insiste Carmen de Burgos es en la práctica generalizada de las falsificaciones en este tipo de negocio, en cómo cualquiera de los anti- 
cuarios referidos en su novela alternaban, en sus ventas, las piezas auténticas con otras prefabricadas en sus talleres, que vendían a ingenuos clientes con una inmejorable pericia puesta al servicio del triunfo de la mixtificación de todo, en el marco de una sociedad fundamentada sobre la compraventa de la mentira.

Pasemos ahora a otra denuncia en la tercera novela prevista, El tío de todos. Aprovechando el paso de uno de sus personajes, Gaspar Garcilaso, por un periódico madrileño, como aprendiz de redactor, Colombine destripa, con cierta zumba, cómo era una redacción por dentro: el casi constante mal humor del director, las reciprocas befas de los compañeros, la división entre los que apoyan al redactor jefe y los que están contra él, la misión censora del responsable, siempre subordinado a la empresa ("Él rara vez escribia, le bastaba con que nadie firmase el artículo de fondo. Su misión era tomar las cuartillas, enviarlas a la imprenta y velar porque no se dijera nada que estuviese en desacuerdo con la opinión "de arriba"" (TT, 81). Así, por ejemplo, resume la triste trayectoria de un eterno meritorio de aquel periódico "que llevaba ya diez años asistiendo puntualmente a la redacción, aguantando reprimendas de los directores, burlas de compañeros, y trabajando más que ninguno, sin cobrar nada, pero contento de poder imprimir en su tarjeta que era redactor de un diario, disfrutar de vez en cuando de un reparto de las localidades de teatro que no lograban vender y de inmiscuirse en todo, zascandileando de acá para allá" $(\Pi, 85)$ y al que llaman, para más inri, Cefiroso; un periodista "ignorante, que no sabía escribir, ni tenía idea de lo que era ortografía, pero se enteraba de todo, traía noticias, desplegaba una rara actividad, y sabía ponerse grave y digno, dando respetabilidad al periódico, aunque lo tenían asustado y más idiotizado que de costumbre, los gritos del Director y las burlas de los compañeros, que le decían, sin miramiento alguno, las mayores enormidades" $(\pi, 85)$. Una redacción llena de ineptos, de corruptos y en donde-la frase está a mitad de camino entre la denuncia y el humor- había un crítico "alto y panzudo, que, por ser sordo hacia con gran justeza la crítica musical" (TT, 87). Y es que la novela a la que me refiero -El tío de todos- es, en su conjunto, una denuncia generalizada de la picaresca, la pequeña estafa y la pillería rodeada de desconfianza que se habían instalado en la sociedad española, o mejor dicho, madrileña, auscultada por Colombine. Otra perspectiva de lo que ya se sacaba a la luz en Los anticuarios.
Hay también en El tío de todos una excelente descripción de la Puerta del Sol como el centro neurálgico de la ciudad, y de los diversos tipos que allí se dan cita para sobrevivir con extraños inventos o diversas prácticas picarescas. Es el mismo ambiente que Carmen de Burgos ya había presentado, y denunciado, en su novela corta de 1919 Los negociantes de la Puerta del Sol, texto que traslada, casi en su totalidad, a esta novela larga, repartiéndola en diversas secuencias de la misma ${ }^{4}$. En este caso le sirve fijarse en ese espacio urbano para poner en contacto al periodista Garcilaso con uno de tales "negociantes", personaje entre patético e irrisorio, que le viene al pelo para colocar la novela a caballo entre denuncia y humor: don Justo, un pobre desgraciado que sueña con resortes de arbitrista que le darán el bienestar que lleva buscando décadas, desde que se vio forzado a emigrar de la provincia a la capital. De la mano de don Justo, Gaspar aprende a conocer la casta de los "puertasolinos", su ingenio y su capacidad de subsistencia, como había mostrado por extenso Colombine en la novelita corta citada ${ }^{5}$. A través de don Justo, Carmen de Burgos nos lleva por un Madrid de miseras buhardillas, de prosapia galdosiana y barojiana, y que tiene bastante del Madrid bohemio que pintara Valle Inclán y que entusiasmaba a Ramón ${ }^{6}$. Tomando como punto de referencia a don Justo, sus inventos y su mísera buhardilla, Colombine hace examen de curiosos especímenes picarescos del momento, denunciando la marginalidad y el abandono social en que vive una buena porción de esa sociedad. Porque, aparte situaciones que conducen al humorismo, en la trama de El tío de todos se detecta la enorme importancia de la picaresca delincuente en la sociedad española, la relevancia del timo y la capacidad autóctona para ingeniarse embustes y tropelías con tal de sacar beneficio de la bonhomía ajena, o de su proverbial tendencia a la codicia. Como dice un personaje de la novela, "Creo que con el ingenio que se pierde en España en esas cosas, empleado en algo útil, llegaríamos a ser un gran pueblo" (TT, 152). Así, en otro pasaje de la misma novela, y refiriéndose a las ocupaciones de don Justo en una agencia de timadores organizados, la narradora nos ofrece un breve catálogo de estafas de la pequeña delincuencia que obraba sobre la buena fe de las víctimas, o se apoyaba sobre su bastardo interés: "se inmoralizaba hasta el punto de contribuir al engaño de otros, aunque siempre en cosas que le parecian de poca importancia, como llevar a un cliente a recibir un préstamo, firmando triple de la cantidad recibida; proporcionar a los pensionistas dinero a peseta por duro al mes, 
sin amortizar; convencer a muchos para que se hiciesen seguros sobre la vida y sobre sus fincas, en la Agencia, cuyos médicos falsos aseguraban cancerosos y tísicos en último grado, cobrando fuertes sumas a las familias, cuya ambición había de quedar chasqueada. Intervenía también en el ramo que la Agencia había destinado a colocaciones, cobrando primas por proporcionar trabajo a dependientes y criadas que, a los pocos días, estaban de nuevo en la calle, porque eran los propios socios los que los admitían. Tenían amas de cría "profesionales" que ofrecian la leche fresca con que habian criado a tres o cuatro muchachos" $(\Pi T, 160)$ y un largo etcétera de esa no erradicable picaresca urbana.

\section{EL HUMOR}

Colombine satirizó y ridiculizó situaciones y personajes como un modo de desactivar una sociedad basada en la fatuidad, la vagancia y la nula fe en el trabajo concienzudo y bien hecho. Una reunión de bohemios afeminados en casa del vizconde Luis de Lara, en la novela El veneno del arte, le da pie para trazar un cuadro lleno de ironía esperpentizante: "Entre los artistas se mezclaban muchos jovencitos dulces, femeninos, soñadores, con los cabellos ensortijados, pintadas ojeras, perfumados y con el cutis lleno de polvos de arroz y de cold cream virginal a la glicerina, que tenían siempre una sonrisa complaciente y una mirada humilde para las más absurdas teorias de los jóvenes genios. Todos llevaban un nombre de guerra. Uno bello, de labios carnosos, ojos grandes, modales deliciosos y ondulantes formas, respondía al nombre de La Manon. Otro, cronista célebre, de gran talento, rostro moreno y aspecto que hubiese sido viril sin la dulzura de una boca de armonioso movimiento femenino, oíase llamar La Reina de Chipre. Un joven de ensortijados rizos respondía al poético nombre de Hada de Invierno; otro, alto, acanutado, con nariz de quilla, contestaba al apelativo de Merluza. Todos los demás estaban también bautizados: la Pelos, la Niapa, hasta el dueño de la casa respondía en aquel mundo al nombre de la Juanona" (VA, 226).

Pero también su ácida mirada se dirige a las aristócratas de medio pelo que gastan lo poco que tienen en afeites y bisutería, para lucir hambrientas en los saraos de abundante repostería, en donde el hambre de semanas les hace dar la nota. Y si no, veamos cómo se comporta la marquesa de la Charca (y ya la ironía se nota desde el mismo título nobiliario): "El apetito de la vieja marquesa era proverbial; de espíritu avaro, procuraba ahorrar en la comida lo que derrochaba en caprichos, y sólo se mantenía de las invitaciones hechas por amigos, que cada vez iban escaseando más. Se la veía con sus bracillos cortos, su abultado abdomen, sentada trabajosamente, con el martirio del corsé recto, sobre el borde del diván, mojar ansiosa enormes pedazos de torta en la taza de Sevres, llena de aromático té, y engullir con apresuramiento a dos carrillos, mientras las plumas de la gorrilla se mecían sobre el pelado cráneo, a impulso del movimiento de las mandíbulas" (VA, 227). Casi un "capricho goyesco". Y hasta en la misma novela es capaz Carmen de Burgos de intentar la autocaricatura en el caso de la escritora feminista, algo ajada, que apuesta por que se atienda, en el arte, a la mujer, presentando féminas "interesantes, cultas, apartar de ellas la escoba y las cacerolas" e insistiendo -dice la misma Colombine en clara autorreferencia- en repetir "un trozo del artículo que en una forma u otra venía escribiendo desde su lejana mocedad: las mujeres lo eran todo, bellas, buenas, sabias, valientes, mucho más que los hombres" (VA, 229).

Y en otro punto del mismo relato El veneno del arte, Colombine se nos descubre capaz de trazar eficaces caricaturas. Una a título de ejemplo, referida al señor de La Llanura: imaginemos un individuo de baja estatura, "rechoncho, con andar de buey gordo" que avanza "con la mano tendida sobre el pecho, entre la abertura de dos ojales de la levita" y que es poseedor de una ostentosa cabeza calva y de una voluminosa nariz "ciranesca, coloradota y granujienta como una berenjena" (VA, 231). Y la distinguida esposa del tal señor es vista por otro participante en el sarao como una "matusalén con pelo de estropajo nuevo, que lleva una carbonería debajo de los ojos" (VA, 232).

En la novela Los anticuarios, tan Ilena de observaciones de primera mano acerca del modo de proceder de quienes pertenecen a esa faceta del comercio, caben varios episodios, a modo de pequeños relatos incrustados en el texto, que son otras tantas ocasiones de llevarnos a la sonrisa y al humor. Uno, por ejemplo, está adjudicado al mismo anticuario protagonista del relato en una de sus salidas a la caza de género barato: "Un día los habían llamado de un pueblecillo de la Mancha para venderles unos tapices que decian ser de la antigua fábrica de Gobelinos ${ }^{7}$. El dueño de 
los tapices y el corredor que los ofrecía estaban entendidos, sabiendo que los tapices eran falsos, para engañar a los anticuarios. Acudieron Fabián y Adelina y todos se dedicaron a obsequiarlos y a ponderar los tapices preciosos. Allí Fabián pudo hablar a su sabor, con el asentimiento de todos, de sus pasadas grandezas, piropear a todas las mozas y examinar las telas de los corpiños que llevaban puestos. Al fin compró los tapices en seis mil pesetas. Yo sé-le dijo a su esposa-que estos tapices son falsos, pero están tan bien imitados que podremos dar el pego con ellos. Y aquel fue el mejor negocio de los que hasta entonces habian hecho, porque los tapices eran verdaderos, y aun dejándose engañar de un anticuario francés, sacaron cincuenta mil pesetas. ¡Una fortunita!" (LA, 34-35)

$Y$ hay humor en la supercheria de tantas ventas fraudulentas por la pericia de los buenos anticuarios, como por ejemplo, aquélla que consistió en endosarle a dos ingenuos clientes estos vulgares objetos, haciéndolos pasar por joyas históricas: "Así vendió la bacía de cobre repujado de un barbero de Tánger como el auténtico Yelmo de Mambrino, y un viejo machete de hierro, en el que había grabadas dos RR por el machete del rey Rodrigo, hallado en el Guadalete. A otro inglés le vendió siete pelos de la coleta del Guerra, con una carta auténtica" (LA, 108-109) Y del mismo Fabián, el anticuario español, se refiere este pingüe negocio que encierra otra viñeta de humor sacada de la misma novela Los anticuarios, incluidas las desacertadas y paradójicas referencias históricas para apoyar la venta de la superchería:

"Habia hecho un mal negocio en Madrid comprando en el Rastro un San Fernando de piedra y otra estatua con traje de romano, en nogal, ambas de tamaño natural y de un peso enorme. Procedian de la iglesia de la Plaza de la Cebada, y amenazaban permanecer siempre en el rincón del almacén sin que nadie cargase con ellas. Un día en que necesitaba reunir dinero para pagar unas letras, Fabián tuvo una inspiración. Embaló cuidadosamente las dos estatuas y se marchó con ellas a Londres, a casa de un rico coleccionista de antigüedades históricas. -Le traigo a usted nada menos que al rey D. Pelayo, vencedor de la morisma, y a su secretario Antonio Pérez -le dijo. El inglés abría la boca viendo los dos enormes cajones-No he querido que nadie los vea antes que Su Gracia-decía el anticuario-Están tal como han llegado de España. Y ante las dos estatuas, que los criados del lord desclavaron cuidadosamente, le contaba la conmovedora historia: -Estas estatuas, que eran veneradas en España, estaban guardadas en la cueva de Covadonga, donde iba el pueblo en romeria a contemplarlas, hasta que, cuando los franceses abandonaron España, Napoleón se apoderó de ellas; y venía ya ominoso de Paris, cuando en el paso de las Termópilas, después de la gloriosa batalla de Bailén, se encontraron con el ejército del general Castaños, que al verlas exclamó: -¿Dónde lleváis esas reliquias tan preciosas? Mientras yo tenga sangre no se consumará ese sacrilegio. Han de volver a su puesto.-Se trabó una refriega, y en el ardor del combate, unos por acercarse y otros por escapar con las estatuas, alcanzaron a éstas algunos golpes. El rey llevó un sablazo en la mano derecha, y le faltan todos estos dedos que ve Su Gracia, y Antonio Pérez un sablazo en la cabeza, cuyas huellas se hallan a la vista. Entonces se hizo el milagro de que los dos -según cuentan los croniconesempezaron a echar sangre por las heridas. Ante el prodigio, fue tal el asombro que Napoleón cayó de rodillas y entregó la espada diciendo: "¡Vuelva el acero a su vaina!". El inglés no podía mantener su gravedad, y lleno ya de entusiasmo, estaba a punto de abrazar al anticuario que tales maravillas le proporcionaba, y acabó por darle 40.000 francos por los dos armatostes, haciendo escribir en una tablilla la grotesca historia. Lo malo fue que, habiendo querido subirlas al piso superior, el peso de las dos estatuas hizo caer el techo, y el pobre don Pelayo se hizo mil pedazos sin echar ni una gota de sangre. El buen lord lo recompuso y apuntó, como un nuevo milagro, el que no se hubiese extraviado ningún pedazo en tan extraordinaria caída. -La suerte está en que no se perdiera la inscripción -decía Fabián- pues estoy seguro que no hubiera podido volver a reconstruirla con tantos visos de verosimilitud... ¡De algo ha de servir la historia!" (LA, 109-111).

Si hay una novela, de las largas, que se sustenta sobre una situación global que mueve a la ironía y al humor, esa novela es El tío de todos. Curiosamente, y salvando las distancian lógicas, su meollo argumental coincide, en lo esencial, con la idea matriz de una reciente película hispano-cubana de Juan Carlos Tabío titulada El cuerno de la abundancia. En la novela de Colombine, la noticia de una muy sustanciosa herencia de un religioso muerto en América revoluciona la población de Palma de Mallorca, porque todos los que alli, o fuera de alli, se apellidan Garcilaso, con las variantes combinatorias de un cambiante segundo apellido, y son legión, se consideran herederos únicos, o casi, de tan codiciado legado. En un pueblecito cuba- 
no, pasando a la película del 2008, todos los apellidados Castañaeiras (y rondan los varios centenares) mantienen ser los herederos de una fortuna depositada en un banco británico (curiosamente como en la novela de Carmen de Burgos) procedente de una herencia de unas monjitas del siglo XVIII. Y del mismo modo que en el film hay un líder que organiza toda la búsqueda del tesoro, en la novela hay un joven periodista apellidado Garcilaso que, además de soñar con escribir y triunfar, se mete en la aventura de ser reconocido el heredero preferente de la susodicha herencia, en disputa con otros personajes no menos ridiculizantes, que aspiran a lo mismo.

En esa galería de posibles acreedores a la cuantiosa herencia -cada vez más numerosos en Europa y en América, hasta el punto de crearse una "Liga Internacional de Garcilasos"-, en las relaciones que se establecen entre ellos, y en el ambiente, a veces mísero, a veces esperpéntico, que los rodea, se percibe una interesante capacidad narrativa para las situaciones de humor, que empiezan por subrayar diálogos de alegres muchachas en sus iniciales escarceos amorosos. Así, por ejemplo, una de la amigas de Lola dice que nunca se enamoraría de un señor de uniforme, por su uniforme, porque "me desenamoraría cuando se lo quitara, y tendría que condenarlo hasta a dormirse de otra de las muchachas cuando refiere que se había enamorado perdidamente, durante un crucero, de un marino observando cómo accionaba en su puente de mando, en el espacio del barco, y del que se sintió profundamente decepcionada cuando lo vio fuera de ese marco en el que se había producido el flechazo: "-¡Que me había de gustar! No he visto figura más ridícula, bien peinadito y vestido a la moda. Sacándolo del puente de su navío era hombre al agua" (TT, 16).

Avanzando en la novela, pronto vamos conociendo nuevos candidatos a la intrigante herencia. Así, el caso de dos ancianas, Ilamadas las Garcilaso Pérez, detectadas por dos anticuarias de baja estofa que estaban buscando mercancía en la isla. La narradora nos presenta a doña Rosalía y a doña Marta, en su delicada situación económica, con rasgos de humor benevolente que nos hace considerarlas de antemano con singular simpatía. Por ejemplo, eran ahorradoras y, a la vez, defensoras de su dignidad de clase pudiente de antaño, hasta el patetismo: "Repartían su dinero para pagar sus cuentas y hacian milagros de ecouniforme" ( $\Pi, 14-15)$, ocurrencia que, en seguida, ratifica nomía para comer con la peseta y cincuenta céntimos que les quedaba para alimentarse. Rosalía, que era la que iba a la compra, entraba todas las mañanas en las principales pescaderias y preguntaba el precio de las langostas y los pescados y mariscos. Luego hacía lo mismo cuando encontraba una carnicería o un puesto de fruta bien surtido. Se enteraba de todo y no compraba nada. Pero se iba satisfecha a contarle a su hermana Marta lo que hubiera podido comprar. Marta cocinaba y no ponía menos de tres platos y postre en cada comida, y platos finos, pastelillos, croquetas, mayonesa de pescado, huevos con tomate, dulces, frutas, ensaladas. No mentían al hablar del admirable menú, pero no hablaban de la cantidad. Con un cuarto de kilo de carne había para toda la semana, un kilo de patatas duraba otro tanto tiempo, y para una tortilla no pasaban de medio huevo. -La gente distinguida no se llena la barrigadecian para consolarse" (TT, 54-55).

Para alegría y medro de despachos de abogados empiezan a surgir Garcilasos por doquier. Desde el capítulo $V$ empezamos a conocer nuevos presuntos herederos de la ya legendaria herencia de la que se afanan por demostrar, cada cual con su argumento, que son los beneficiarios más apoyados por la legalidad. Escuchamos razonar, al respecto, a dos afectados por la pluralidad de candidatos:

"-Pero si ahora parece que somos Garcilaso media España. ¿Cómo vamos a ser parientes todos?

-Como de la semilla del primer árbol, nacieron todos los demás árboles" (T, 73).

Al hilo de la superchería central de la novela -una cuantiosa herencia que, finalmente, queda en el globo deshinchado de una vana ilusión- la narradora tiene ocasión de contarnos graciosas anécdotas surgidas de otras tantos timos de medio pelo, como la de aquel ingenuo lugareño, enamorado de la alcaldesa de su aldea, que aceptó la propuesta de que lo hicieran invisible para que así pudiese lograr acceder hasta la mujer que, de otra manera, le resultaba inasequible del todo: "Los inventores del procedimiento lo llevaron a la Agencia y después de estarle dando unturas varios días declararon que ya era invisible. El hombre salió entre los servidores y amigos, reunidos a propósito, que fingieron no verlo. El director y el secretario lo llevaron en coche a la estación y sólo pagaron la carrera de dos personas, sin que el cochero viese que eran tres. El buen hombre llegó a su pueblo y sin más ni más corrió

ARBOR CLXXXVI EXTRA JUNIO 2010 73-84 ISSN: 0210-1963

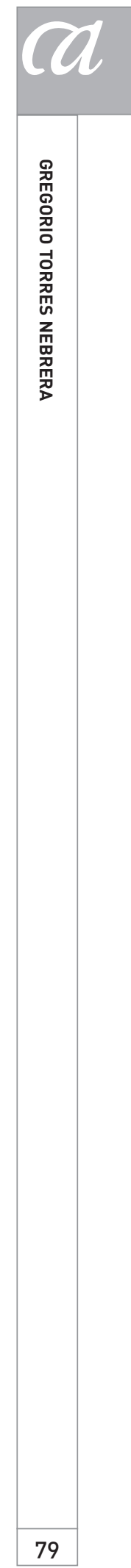

doi: 10.3989/arbor.2010.extrajunion3009 
a abrazar a su adorada... Cuando se curó de la paliza que le dieron, volvió a Madrid y acabó a su vez a palos con la Agencia" ( $\Pi, 164-165)$. 0 la estafa de la máquina que imprimía billetes de banco falsos al precio de cuatro mil pesetas de las auténticas.

En la novela Colombine aprovechó algunas de sus experiencias viajeras, y asi nos trasladamos con el periodista Garcilaso hasta la ciudad de Londres, para resolver de una vez la verdad o la mentira de la dichosa herencia. Como París en Los anticuarios, en esta novela se nos da, en pocas líneas, una cumplida información -guía para visitar la capital inglesa, con lo mejor y lo peor de la misma, al ritmo de las andanzas del protagonista en aquella ciudad, yendo de los "barrios pobres y pintorescos" a los "barrios aristocráticos y suntuosos". Y, al fin, para saber la verdad, y conclusión, de la superchería que había hecho pensar en grandezas a tantos y a unos pocos había llevado a la ruina de sus escasos bienes: la única heredera legal de la herencia que hubiese podido dejar el monje apellidado Garcilaso, tras su voto de pobreza, era la orden en donde había profesado y en cuyo seno había muerto. De nuevo una sociedad danzando en torno de su majestad la mixtificación. El humor es, como ha sido siempre, otra vía eficaz de denuncia: el viejo "castigat ridendo mores".

\section{LA PASIÓN}

Claro está que la pasión más genuina en la narrativa de Colombine va acompañada del calificativo especificativo de "amorosa", y a un ejemplo claro, al respecto, me referiré enseguida. Pero hay pasiones de otra índole que también arrebatan a los personajes de sus novelas. Sin abandonar el escaso corpus que he elegido en esta ocasión, en Los anticuarios es la mujer Adelina la que anida en sí esa pasión personal y profesional por comprar, vender y acumular a su alrededor testimonios materiales del pasado, desde que empezara a vender algunos objetos de los propios de este mercado entre vecinos y amigos, de una forma muy artesanal, propia de aficionada. Pero una afición que fue creciendo hasta convertirse en una pasión imposible de refrenar. Por ello, cuando después de una operación de suerte que le supone la posibilidad de traspasar el negocio y retirarse a vivir ociosa en el Madrid de su origen (operación que consistió en una nueva mixtificación: vender como auténtica una excelente copia de Fra Angélico) la anticuaria Adelina no puede conciliar el sueño la noche antes de entregar su tienda parisina al colega que se la ha comprado, y decide, con la complicidad de su marido, romper el compromiso adquirido y aprestarse a abrir el establecimiento, otra vez, a la mañana siguiente, como al comienzo de la novela ${ }^{8}$. Adelina se da cuenta de que la decisión de jubilarse de la profesión ejercida y defendida durante tantos años era una palmaria equivocación: "Se encontraría ya siempre descentrada, con esa nostalgia del marino que abandona su barco. Tenía hacia su tiendecita un amor marino a las tablas del camarote que le sirve de refugio en las tempestades. Su tienda era su barco, su camarote, el lugar donde había pasado la mayor parte de su vida" (LA, 323). Traspasar su negocio de antigüedades, en el que la mujer había volcado todo su trabajo, su esfuerzo y sus sueños de prosperidad le daba una dolorosa sensación de despojo: "la despojada era ella; ella que lo había hecho todo, que lo había creado todo, que amaba su profesión como a sus hijos, porque había puesto también en ella corazón, carne y alma" (LA, 324). Y es que la pasión también puede inocular el trabajo en el que se cree, la profesión en la que nos sentimos realizados personal y socialmente. Adelina era consciente de que fuera del gremio de anticuarios su protagonismo caería en el olvido, en la ignorancia, en el ridículo e incluso en el desprecio. Ella se había hecho en ese gremio y a ese gremio pertenecía, sin posibilidad alguna de transmigración social, salvo que accediera a sentirse tocada por el baldón del intrusismo. $Y$ eso es lo que justamente le mueve a la anticuaria a tomar una irrevocable decisión: "Su profesión había impreso en ellos carácter. Eran anticuarios, anticuarios para siempre, no podian dejar de serlo. Su corazón estaba pegado a su comercio, era imposible arrancarse a él sin una mutilación dolorosa y mortal" (LA, 325). La pasión, en fin, que determina el decurso de unas vidas.

Pero también, y dentro del apartado de la pasión amorosa, hay pasiones pragmáticas, presididas por la cabeza y el orden, o sea, pasiones descafeinadas. Y una de esas pasiones es la que decide sentir el joven Gasparito Garcilaso, de la novela El tío de todos, por su enamorada Lola, y no la romántica pasión de enfrentarse a la oposición paterna, raptar a la enamorada y ponerse el mundo por montera. Muy al contrario, el prudente Gaspar decide reconvertir su pasión en el encasillado y domesticado camino de hacerse antes un hombre de provecho, planteándose estas 
burguesas reflexiones: "No se ama a una mujer, si no se la honra y se conquista un modo de vivir para no obligarla a sufrir privaciones" ( $\Pi$, 32-33), dándole razón, en parte, a la exigencia del padre de la chica de sólo casarla con un buen partido, porque "para mi padre no hay talento sin dinero. Él juzga a las personas por lo que ganan. Un comerciante de ultramarinos tiene para él más talento que Campoamor" $(\Pi, 34)$. Claro que a lo largo de la novela Gasparito Garcilaso tendrá atisbos de lo que puede ser una verdadera pasión cuando ha de plantearse la posibilidad de alejarse de una prima conocida en Madrid y de la que está enamorándose con gran rapidez. Analiza entonces la diferencia entre la no-pasión que experimenta por la novia mallorquina y la posible pasión que le arrebata a favor de la madrileña. "Aquel amor por Solita era más violento, más avasallador. Le gustaba por sus gracias, por sus coqueterías, por sus puerilidades. Quizá la misma falta de seguridad en ser amado agudizaba su pasión" $(\pi, 215)$. Una pasión que, sin embargo, Gasparito, nada dado a compromisos para más de un rato, supo domeñar a tiempo, neutralizar en su corazón de "romántico enamorado", en el que, paradójicamente, lo pragmático y lo prudente ganaban la partida.

Pero la novela, o una de las novelas, en la que la pasión, amorosa por supuesto, tiene verdadero predicamento es la titulada Puñal de claveles, uno de los últimos títulos de Carmen de Burgos, y uno de sus relatos más contenidos, tensos y mejor construidos. Tal vez sea su novela más famosa por razones extrínsecas a su texto, pues, como es bien sabido, nuestra autora se inspiró en el mismo dramático y sangriento suceso del crimen del Cortijo del Fraile, en los Campos de Níjar, en 1928, cuando una boda acabó en el homicidio cometido en la persona del hombre que se escapaba con la recién casada, el suceso que, en las prodigiosas manos de García Lorca, se convirtió en la tragedia Bodas de sangre. Pero, fuera del paralelo con el texto lorquiano, que no es pertinente hacer ahora, la propuesta de Colombine, a partir de ese común hecho referencial, tiene unos valores literarios tan considerables que, me parece, permiten considerarla como una de sus mejores novelas. Y empezando por la metáfora del propio título que, curiosamente, y por separado, fue una metáfora igualmente pertinente en la obra lorquiana, en donde el puñal -o la navaja, instrumento de la muerte- tiene un marcado protagonismo desde el comienzo al final de la tragedia, y en la que igualmente el motivo floral, unido a la ceremonia nupcial, alcanza también un simbolismo muy notable 9 . De parecido modo en la novela de Colombine, en la que la pasión ata, arrastra, y puede destruir o salvar, según la capacidad de cada cual en responder a sus reclamos, el binomio flor/mujer alcanza una fuerza telúrica y erótica inconmensurables.

Cinco breves capítulos, todos titulados, fragmentan el texto. Conviene recordar esos títulos, que ya nos dan una pista del diseño de la novelita: I "La primera amonestación", I| "El ramo de flores", III "El embrujamiento del perfume", IV, "La revelación" y V, "Doble pasión". Cinco secuencias de muy desigual extensión, siendo, con mucho, la más larga la primera (porque en ella hay que explicar ciertos antecedentes que sitúen la acción en sus coordenadas concretas, y no poco del costumbrista ritual del casorio) y de una extensión promediada las siguientes, salvo la cuarta -toda revelación es algo que surge con el fulgor y la rapidez de un relámpago- brevísima en su misma intensidad. Y notemos también algo relacionado con los títulos: la secuencia situada en el centro del quinteto conlleva la clave simbólica de la historia alli desarrollada: todo ocurre como efecto de una causa previa, el efecto seductor, embrujador de un ramo de claveles, más su aroma que su color, el arrebato de su intenso perfume.

El perfume es una sensación sensual que resulta crucial en el texto. Ya en su segundo párrafo leemos "Un intenso olor a día de primavera lo envolvía todo de un modo penetrante", sin pasar por alto la asociación semántica del adjetivo "penetrante" con el "puñal" que se enuncia en el título, y con toda la carga erótica (y de violencia) que a su vez conlleva este vocablo.

La protagonista, que se atreverá al abandono del cortijo horas antes de su boda, se llama Pura, y lo es porque en ella no hay más transgresión que acceder a un instinto de libertad y a la llamada de la pasión, de la verdad, que su condición de mujer encerrada, limitada, le acaba exigiendo. Pura es rica, hermosa, joven, pero triste, recluida en un cortijo en medio del desierto de Nijar, con ansias de escaparse de un espacio/cárcel que la ahoga cada día. Y no sólo porque el espacio vital de Pura es un cortijo aislado en medio de la nada ${ }^{10}$, sino también (y ello es uno de los hallazgos argumentales de Colombine) porque ese cortijo es limitrofe con un recoleto cementerio en donde habían ido quedando las mujeres anteriores de aquella hacienda, de un cortijo cuyo fundador y primer propietario - un carlista apodado

ARBOR CLXXXVI EXTRA JUNIO 2010 73-84 ISSN: 0210-1963

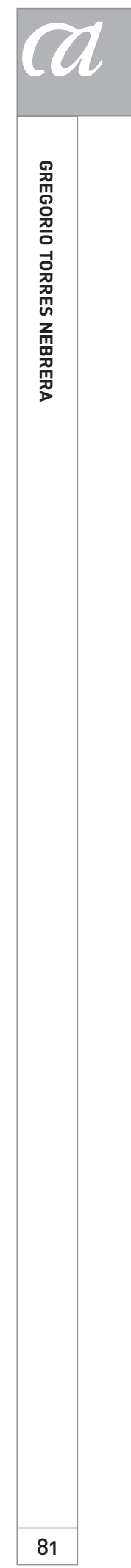


"El Monje"- huyó también un día, espantado del espacio de cárcel-muerte que había terminado por crear en aquel paraje. $Y$ esa historia pesa, consciente o subconscientemente, sobre la psique de la muchacha protagonista, que confiaba en su inmediato matrimonio como un medio de liberación. La mujer y la hija del solitario cortijero habian fallecido "como flores marchitas, faltas de ambiente". Esta metáfora comparativa, aunque tópica por repetida, es en este contexto muy pertinente. La oposición flor seca, marchita, artificial/flor viva, pujante, olorosa es una oposición fundamental en la pasional historia de la inquieta Pura.

La oportunidad de salir de aquellos límites había llegado con la proposición de otro hacendado cortijero de las proximidades. Pero sin pasión de por medio. Colombine echa mano del matrimonio de conveniencia, del topos de la pareja viejo-niña. Los preparativos de la inmediata boda se llenan de regalos abundantes, en cantidad y calidad, que incrementan el rico ajuar, y que suscitan en la novia un peligroso pensamiento de frustración: "le parecía que lo tenía todo para su boda, menos el novio" (PC, 78), porque Pura es consciente de que el marido que le han dispuesto "no era para despertar su pasión" (PC, 78) y que el paso que se disponía a dar equivalía a "entrar en las obligaciones y esclavitud de las casadas" (PC, 79) Y entre los regalos, uno en el que la narradora se detiene: un par de "flores contrahechas", dos rosas artificiales, "de tamaño descomunal, sobre hojas de papel de talco" (PC, 64), que, aún gustándole a la mujer, no le apasionan en absoluto, y las rechaza. Lo contrario de lo que ocurre con un segundo regalo, aparentemente de su prometido: un ramo de claveles naturales, intensamente rojos, que la novia huele con verdadera delectación y "cuando levantó la cabeza estaba pálida y parecía que se había encendido en sus pupilas azules una luz extraña" (PC, 80). El portador del ramo es José, el hombre que, como Pura, desea escapar de aquellas tierras hacia un nuevo horizonte, el hombre que la desea, el sujeto de una pasión, de momento refrenada, hacia la hermosa doncella. Un ramo que ha hecho su efecto: Pura se siente atraída por su intenso perfume: "la poseían los claveles, con el aroma que la penetraba como un puñal" $(P C, 83)$. No deben pasar inadvertidos los verbos elegidos por la novelista: "poseer" y "penetrar". Y la mujer asocia aquel ramo de olor inagotable con el hombre que verdaderamente la puede hacer feliz, y que no es el destinado para marido (para siempre asociado con las flores contrahechas, inodoras en su aparente belleza) sino el otro, que en la noche última anterior a la boda reitera su ofrenda floral y sustituye, en la consciencia de Pura, al no deseado marido. A través del símbolo de los claveles encendidos, y oliendo intensamente a clavo, se alimenta una pasión auténtica, llena de vida y de verdad, que salta por encima de los códigos de clase, de los rituales campesinos, de los intereses crematísticos que resecan el amor conyugal como si estuviera hecho de flores de papel, sin olor y sin rocío en sus pétalos. Ante el nuevo ramo, la virgen desnuda, ofrecida, enmarcada en la ventana de su cuarto todavía de soltera, comprende: "No era Antonio el que la hacía temblar de amor, era José el que la envolvía en su caricia con aquel perfume penetrante como un puñal que penetraba en su carne" (PC,90), volviendo asi la narradora a la erótica metáfora que da título a su relato. El desenlace es esperable. En la madrugada de la boda, Pura y José, a lomos de un rápido caballo, es decir, arrebatados sobre su doble pasión, huyen del cortijo que tantas resonancias de convento y de muerte tenía, hacia una vida compartida en libertad. Porque en el desenlace que le da al rapto Carmen de Burgos no hay derramamiento de sangre bajo la luna, como decidió Lorca, sino triunfo de la vitalidad, de la pasión que sale por sus fueros. Colombine acaba exaltando el poderío, en la tierra andaluza, de lo sensual, activado por el olor de una naturaleza pujante, que invita al goce casi pagano. Las últimas líneas de esta novelita insisten en cómo el aroma de los campos, de los cuerpos y del aire ayudan a espolear la carrera hacia la entrega, tras el rapto, emulando los rituales nupciales primitivos. La doble pasión de Pura y José era el tributo a un mandamiento telúrico concentrado en un oportuno y expresivo ramos de claveles: "La clave de la pasión andaluza estaba en la sensualidad de los perfumes de su tierra" (PC, 101). 
breves de escritoras españolas (19001936) a cargo de Ángela Ena Bordonada. Madrid, Castalia, 1990.

5 El capítulo XII de El tío de todos es una espléndida sintesis de los antecedentes históricos de la emblemática plaza (en donde transcurre una buena parte de la novela) y de cómo en aquella auténtica "corte de los milagros" se daba cita lo mejor de la picaresca y de la estafa madrileña de aquel tiempo, especialmente en sus numerosos cafés. Pero es un capítulo escrito casi totalmente con los materiales ya utilizados en la novelita Los negociantes de la Puerta del Sol.

6 Se nota en la excelente descripción de la popular vía urbana el interés de Ramón por los espacios madrileños, y su posible influjo en el lenguaje descriptivo de la narradora. Así, en ocasiones, llega a emular la greguería, como en este ejemplo: "Los comercios cubrian sus escaparates, se cerraban las ventanas; sólo los que iban a sus quehaceres pasaban apaisados por las aceras. Era la hora de las citas; la hora de la sobremesa; cuando los hombres se reunían en los cafés para tratar sus asuntos" (TT, 95; el subrayado es mío). En Los negociantes de la Puerta del Sol había escrito de Burgos: "Ios comercios cubrian sus escaparates; se cerraban las ventanas; sólo los que iban a sus quehaceres pasaban espaciados por las aceras. Esta era la hora de las citas; la hora de la sobremesa; cuando muchos hombres podian marchar reunidos al café para tratar mejor un asunto". Idéntico texto, cuya única diferencia está en la expresión cercana a la greguería "apaisados" frente a "espaciados". Probablemente el interés de ambos escritores por la famosa vía madrileña fue mutuo, y mutuamente se influyeron en ese
4 Apareció en "La Novela Corta" el 27 de septiembre de 1919. Hay reedición moderna en el volumen Novelas
Aceptado: 7 de junio de 2010
Recibido: 14 de mayo de 2010

doi: 10.3989/arbor.2010.extrajunion3009 
sentido. Recordemos que Ramón publicó, poco después de Los negociantes..., en 1920, el libro Toda la historia de la Puerta del Sol (luego, en 1931, refundido en el nuevo libro Elucidario de Madrid) en donde cita algún fragmento de la novela de Colombine, además de elogiarla. Por otra parte tanto de Burgos como Gómez de la Serna no hacian sino responder a un asunto que estaba de moda en la literatura costumbrista-descriptiva de la época, según lo muestran diversos textos periodísticos de aquellas fechas debidos a Francos Rodríguez, Donosty, Emilio Ramírez Ángel, etc.

7 Famosísimo taller parisino de tapices fundado por Enrique IV en 1601, y ampliado por el ministro de Luis XIV Monsieur Colbert, y que fue instalado en la casa de los tintoreros Ilamados "Gobelinos".

8 Así empieza Los anticuarios: "Antes de abrir la tienda era preciso dar un último vistazo a los géneros y ponerse todos de acuerdo acerca del precio de algunos artículos dudosos. Ellos no necesitaban dependientes, se lo arreglaban todo en familia" (pág. 5) y así leemos en su últimos párrafo: "En seguida ella acabó de abrochar su vestido, deprisa, y salió de la alcoba contenta, sonando las llaves en su manecita pequeña y gordezuela y gritando con voz alegre mientras rompía los letreros -'Cerrado por traspaso'en pedazos tan pequeños que caían como confetti en el suelo: -iArriba Enrique! ¡Arriba Fabián, que es tar- de! iiVoy a abrir la tienda!!" (págs. 325-326).

9 No hace falta recordar que la obra de Lorca se abre y se cierra con la prevención y el dolor que producen en la madre la navaja que lleva el hijo para cortar las uvas de las viña, la misma navaja con la que le será cortada la vida: una navaja "que apenas cabe en la mano,/ pero que penetra fino/ por las carnes asombradas,/ y que se para en el sitio/ donde tiembla enmarañada/ la oscura raíz del grito". E igualmente debe recordarse cómo se juega con las simbólicas y metafóricas referencias a las flores a todo lo largo de la tragedia, Así, en el primer diálogo entre Madre y Novio ya oímos decir a la primera que "tu padre, que me olía a clavel y lo disfruté tres años escasos". Al comienzo del cuadro segundo del acto primero se oye la nana cantada al hijo de Leonardo, con este reiterado estribillo: "Duérmete, clavel,/ que el caballo no quiere beber". Y la Novia metaforiza su pasión por Leonardo con esta imagen floral: "Es como si me bebiera una botella de anis y me durmiera en una colcha de rosas" A este respecto puede consultarse el trabajo de Luis T. González del Valle (1977). Cito por García Lorca (1997: 474, 417, 422 y 438 respectivamente).

10 "El cortijo era grande, tenía cierto aspecto feudal cuando se le veía de lejos, porque al estar en la hondonada hacía que se descubriese el ex- tremo de los arcos de las tinadas de las reses y tenía cierto aspecto de claustro que rimaba con la puerta del cementerio y los cipreses puntiagudos y tristes" (PC, 75).

\section{BIBLIOGRAFÍA}

Burgos, Carmen de (1989): El veneno del arte (en el volumen La flor de la playa y otras novelas cortas), Madrid, Castalia, ed. de C. Núñez Rey.

- (1919): Los anticuarios, Madrid, Biblioteca Nueva.

- (1925): El tío de todos, Barcelona, Rivas y Ferrer Editores.

- (2009): Puñal de claveles, Almería, Instituto de Estudios Almerienses. Diputación Provincial (con estudios de Anyes Segura, Antonio Sevillano, Diego Martínez y Elisa María Martínez Garrido).

- (1919): Los negociantes de la Puerta del Sol, Madrid, "La Novela Corta", Año IV, n. 195.

García Lorca, Federico (1997): Obras Completas II. Teatro, Barcelona, Galaxia Gutenberg, Círculo de Lectores (edición de Miguel García-Posada).

González del Valle, Luis T. (1977): "Metáfora y símbolo en Bodas de sangre: la dimensión estética de las flores", Segismundo. Revista hispánica de teatro, Madrid, CSIC, 25-26, pp. 327-348.

Núñez Rey, Concepción (2005): Carmen de Burgos, Colombine, en la Edad de Plata de la Literatura Española, Sevilla, Fundación José Manuel Lara. 